\title{
Assessment of implantable drug delivery technology: poly (3-hydroxybutyrate) / polypropylene glycol films containing simvastatin
}

\author{
Lays Fernanda Nunes Dourado ${ }^{1}$, Amauri Pierucci ${ }^{2}$, \\ Juan Pedro Bretas Roa ${ }^{3}$, Álvaro Dutra de Carvalho Júnior ${ }^{1}$
}

\footnotetext{
${ }^{1}$ Department of Pharmacy, Federal University of the Jequitinhonha and Mucuri Valleys, Campus JK, Rodovia MGT 367 - KM 583, n 5000 Alto da Jacuba, Diamantina, Minas Gerais, Brazil.

${ }^{2}$ Department of Basic Sciences, Federal University of the Jequitinhonha and Mucuri Valleys, Campus JK, Rodovia MGT 367 - KM 583, n 5000 Alto da Jacuba, Diamantina, Minas Gerais, Brazil.

${ }^{3}$ Department of Science and Technology, Federal University of the Jequitinhonha and Mucuri Valleys, Campus JK, Rodovia MGT 367 - KM 583, n 5000 Alto da Jacuba, Diamantina, Minas Gerais, Brazil.

e-mail: laysndourado@gmail.com, amauri_pierucci@hotmail.com,juan.roa@ict.ufvjm.edu.br, alvaro.junior@ufvjm.edu.br
}

\begin{abstract}
Natural polymers have attracted much attention in recent years for the study of new drug delivery systems. These materials are used as polymer matrices to protect the active drug from degradation in the biological environment and to improve the release kinetics of the drug. The poly(3-hydroxybutyrate) (PHB) is a natural biocompatible polymer, widely used in combination with other polymers to improve their physicochemical properties. Thus, this work aimed to develop and characterize films of PHB and blends containing polypropylene glycol (PPG) with different concentrations of simvastatin (Simv.). The films were prepared by casting, dissolving PHB or a blend of PHB / PPG (90:10) and (5\% or $25 \%)$ Simv. in chloroform (2\% w/v). The solutions were stirred for $3 \mathrm{~h}$ and then transferred to an appropriate glass mold for solvent evaporation for $48 \mathrm{~h}$ at room temperature. The obtained films were characterized by Fourier Transform Infrared (FTIR) spectroscopy, thermogravimetric analysis, scanning electron microscopy (SEM), optical microscopy, in vitro degradation study, and in vivo biocompatibility test. The results showed that PHB and blends of PHB / PPG are able to form a homogeneous film with the drug inside. A great amount of drug lead to the instability of polymeric matrixes and resulted in a facilitated film degradation. On the other hand, devices with $5 \%$ of Simv. were more stable, which suggests the application of these films for biomedical devices. In vivo studies revealed that the films can interact with the animals' organism, and do not undergo rejection. Hence, these films hold an innovative alternative in tissue engineering to promotes drug release by diffusion and erosion of the polymeric material.
\end{abstract}

Keywords: Polymeric scaffolds. Tissue engineering. Biofunctional materials. Biocompatibility.

\section{INTRODUCTION}

Medical devices and implants comprise an important tool in regenerative medicine to improve the quality of daily life and extending the functionality of the body systems [1,2]. Biomedical research has been investing in devices that can replace the origin tissue and also treat the problem [3-5]. In view of this, polymers have been widely used for this purpose due to their excellent bio-functionality, low cost, and good mechanical properties [6].

In the pharmaceutical field, polymers play a significant role in the development of medicines and they are gaining attention because they can achieve a delivery drug over a longer period [7]. For this, they are employed in various types of formulations such as microparticles, nanoparticles, microspheres, and others [810]. When a polymeric system is introduced into the body, the release of the drug occurs by a combination of its diffusion and polymer degradation. Sequentially, the empty device remains at the site of administration or is degraded to inert, nontoxic, and biocompatible degradation products [11]. 
Polymers are macromolecules composed of many repeated subunits (monomers). They are classified in two main categories: natural and synthetic. In recent years, natural polymers have attracted much attention because they are derived from renewable sources and are capable of breaking down into minor molecules, that can be metabolized and removed from the body via normal metabolic pathways $[12,13]$.

The polyhydroxyalkanoates (PHAs) are natural polymers produced by many bacterias in the form of intracellular granules, composed basically of carbon, oxygen and hydrogen [14-16]. Among various PHAs, poly(3-hydroxybutyrate) (PHB) is the most prominent representative homolog of this family. This biopolymer has physical and mechanical properties very similar to polypropylene (PP) and has shown tremendous potential for drug delivery vehicles and biomedical devices [17-19]. Moreover, the PHB offers attractive alternatives for the inconveniences of the petrochemical polymers [20,21].

PHB has been extensively considered for biomedical devices [22-24]. An example of this is the blends of PHB with hydroxyapatite that have been studied in tissue engineering and regenerative medicine applications [23]. Moreover, given the advances from the past few decades of research, PHB-based materials are emerging as a potential drug delivery system [25, 26]. Likewise, these biomaterials may also be further modified to deliver bioactive substances and have their function optimized. For instance, in a study developed by HEYDARI et al. [27], PHB nanofibers with the sequential release of ciprofloxacin and Simvastatin (Simv.) were prepared for wound dressings to control infections and reduces wound healing duration.

Despite the numerous applications, PHB has limited stability at high temperatures, which limits its use in the pharmaceutical industry [26]. To overcome this problem, PHB is to blend with others polymers to improve their physical characteristics and their processing and cost [28, 29]. In the literature, there are many studies of PHB blends for potential medical applications, within which stand out some polymers like poly(ethylene glycol) (PEG), poly(caprolactone) (PCL), cellulose, chitosan, poly(lactic acid) (PLA), and others [26, 30-33].

In this context, a study performed by ROA et al. [34], provided evidence of a decrease in the crystallinity and on the melting temperature of PHB after the addition of poly (propylene glycol) (PPG), one type of thermoplastic that is mostly used as biomaterials for fabrication of biomedical devices. PPG has a simple structure that contains carbon, oxygen and hydrogen, and consists of a viscous, hygroscopic, and odorless fluid. Compared to PEG, PPG is less toxic, shows good solubility, high chemical stability, is biocompatible, and biodegradable [35]. Thus, PHB/PPG blends result in a polymeric material with a higher degradation temperature, which represents a gain in its mechanical properties and possibilities of usage [28, 34].

On the other hand, statins have been used in new therapeutic trends, that were previously unknown, and have presented satisfactory results, which broaden the research on this class of drugs. Some studies confirm the efficacy of statins in cancer, bone remodeling, dementia, among other diseases [36, 37]. Simv. is the most widely marketed drug among statins. This drug has low solubility in an aqueous medium; however, it has high permeability. Thus, the development of polymeric devices containing Simv. contributes to improving the bioavailability of this drug [38-40]. Moreover, statins are capable of promoting osteogenesis and contribute to bone fracture consolidation [41, 42]. Thus, biomedical devices containing Simv. can enhance implant osseointegration.

According to our review of the literature, no study has been performed to evaluate the application of PHB/PPG blends for a biomedical device or their capacity for drug delivery. Therefore, the aim of this work was to develop and characterize films of PHB/PPG blends containing different concentrations of Simv. and after investigate the biocompatibility of these devices by in vivo study.

\section{EXPERIMENTAL}

PHB $(\mathrm{Mw}=600 \mathrm{kDa})$ was purchased from PHB Industrial S/A (São Paulo, Brazil). The PPG $(\mathrm{Mw}=1 \mathrm{kDa})$ was obtained from Aldrich (Missoure, USA). Simv. was purchased from Henan Top fond Pharmaceutical (Zhumadian, China). Chloroform and ethanol were obtained from Vetec (Rio de Janeiro, Brazil). All chemicals were of analytical grade, and distilled water was used throughout.

\subsection{Preparation of PHB/PPG blends and films}

The polymeric blends were prepared by casting. PHB was solubilized in chloroform at $40^{\circ} \mathrm{C}$ through constant stirring until complete dissolution of the polymer. The PPG was added in the concentration of 10\% (v/v), and 
then the solution was stirred and left to stand at room temperature until complete solvent evaporation. After the preparation of the blends, films were obtained by dissolving PHB or blend (PHB/PPG 90:10) and Simv. $(5 \%$ or $25 \%)$ in chloroform $(2 \% \mathrm{w} / \mathrm{v})$ as presented in table 01 . The solutions were stirred for $3 \mathrm{~h}$ and transferred to an appropriate glass mold for solvent evaporation for $48 \mathrm{~h}$ at room temperature. After evaporation of the solvent, the films were prepared in disks of $5 \mathrm{~mm}$ diameter and $0.5 \mathrm{~mm}$ thickness, weighing between 5 and $10 \mathrm{mg}$ each.

Table 1: Composition of PHB or PHB/PPG films.

\begin{tabular}{c|c|c|c}
\hline FILM & PHB & PPG & Simv. \\
\hline PHB & $100 \%$ & - & $5 \%$ \\
\hline PHB 5\% Simv. & $95 \%$ & - & $25 \%$ \\
\hline PHB 25\% Simv. & $75 \%$ & - & - \\
\hline PHB/PPG & $90 \%$ & $10 \%$ & $5 \%$ \\
\hline PHB/PPG 5\% Simv. & $85,5 \%$ & $9,5 \%$ & $25 \%$ \\
\hline PHB/PPG 25\% Simv. & $67,5 \%$ & $7,5 \%$ & \multicolumn{2}{|c}{} \\
\hline
\end{tabular}

\subsection{Characterization of films}

The films were characterized by molecular absorption spectroscopy in the infrared region with Fourier Transform Infrared (FTIR) spectroscopy, thermal analysis techniques, optical microscopy, scanning electron microscopy (SEM).

FTIR was performed using a spectrophotometer (Perkin Elmer Spectrum 100 FTIR Spectrometer, USA) and combined with an attenuated total reflection (ATR) assembly. Small pieces of films (PHB, PHB/PPG, PHB with $5 \%$ of Simv., PHB with $25 \%$ of Simv., PHB/PPG with $5 \%$ of Simv., PHB/PPG with $25 \%$ of Simv.) and Simv. (pure drug) were placed on a crystal and the maximum force was applied using a pressure clamp to allow for optimum contact with samples. The FTIR spectra were recorded within the range of 4000 to $700 \mathrm{~cm}^{-1}$ and a uniform resolution of $4 \mathrm{~cm}^{-1}$.

Thermal analysis curves were obtained in an STA 8000 simultaneous thermo-analyzer (Perkin Elmer, Germany). Samples weighing between 2 and $5 \mathrm{mg}$ were used. The analysis was performed in the temperature range of 30 to $500^{\circ} \mathrm{C}$ under $\mathrm{N}_{2}$ atmosphere. Temperature programming used was: 2 minutes isotherm at $30^{\circ} \mathrm{C}$, then heating to $500^{\circ} \mathrm{C}$ at $10^{\circ} \mathrm{C} \mathrm{min}^{-1}$ and a second isotherm for 2 minutes at $500^{\circ} \mathrm{C}$.

\subsection{Morphological analysis}

The microphotographs of films were obtained using a polarized microscope (Olympus BX41, Japan) attached to a camera (UC30, Germany). The images were recorded at 10× magnification under bright and polarized light.

The ultra-morphology of the produced films was examined using a scanning electron microscope DSM940-A (Zeiss, Germany), at $3 \mathrm{kV}$. The samples were fixed in metallic support and then subjected to metallization, performed using a sputtering technique on the Q150R ES (Quorum Technologies, England).

\subsection{In vitro degradation test}

In vitro tests were conducted based on the behavior of the films in simulated physiological environment [43, 44]. About $1000 \mathrm{mg}$ of sample was placed in falcon tubes containing $10 \mathrm{ml}$ of phosphate-buffered saline (PBS), $\mathrm{pH} 7.4$. The tubes were kept at room temperature $\left(25 \pm 5^{\circ} \mathrm{C}\right)$ for predetermined time points: $30,60,90$, 120, and 180 days. Then, samples were removed from PBS and stored for $72 \mathrm{~h}$ in the desiccator. Films were dried and then weighed with a scale. Weight loss was calculated according to Eq. 1:

$$
\text { Weight loss }(\%)=\left(\frac{W 0-W 1}{W_{0}}\right) \times 100
$$

Where: W1 and W0 are the weight of samples after degradation (180 days) and the initial weight before degradation, respectively. 
For each group, six independent experiments were done for each time point. Cumulative weight loss was presented as mean \pm standard derivation (SD). GraphPad Prism version 8.4.2 for Windows was used for making the graph.

\subsection{In vivo biocompatibility test}

In vivo study was carried out in a mouse model with the approval of the ethics committee in experimental animals of the Federal University of the Jequitinhonha and Mucuri Valleys (Protocol $\mathrm{n}^{\circ}$ 44/2015). Swiss mouse, male, albino, weighing between 25 and $40 \mathrm{~g}$, approximately 120 days old each, were used. Animals were kept under controlled conditions of temperature $\left(25 \pm 5^{\circ} \mathrm{C}\right)$ and luminosity $(12$ hours light $/ 12$ hours dark) with food and water ad libitum.

Before surgical procedures, the animals were anesthetized with an intraperitoneal injection of 1:1 xylazine/ketamine (Ceva, Brazil) at a dose of $0.10 \mathrm{ml} / 100 \mathrm{~g}$. Animals were placed in ventral decubitus position and a trichotomy was performed in the dorsal region. After asepsis, a longitudinal incision of $0.5 \mathrm{~cm}$ was made with the scalpel on the skin. One disc of $5 \mathrm{~mm}$ diameter and $0.5 \mathrm{~mm}$ of thickness was inserted, and skin was sutured.

The films inserted were: PHB, PHB/PPG, PHB containing 5\% of Simv. (named as PHB 5\% Simv.), PHB containing $25 \%$ of Simv. (named as PHB 25\% Simv.), PHB/PPG containing 5\% of Simv. (named as PHB/PPG 5\% Simv.), and PHB/PPPG containing 25\% of Simv. (named as PHB/PPG 25\% Simv.). Six animals were used in each group. The animals were sacrificed after 60 days. A group without any surgical procedures was used as a control. Animals were euthanized with Thiopental (Thiopentax; Cristália, Brazil) $60 \mathrm{mg} / \mathrm{kg}$.

In the immediate postmortem, a regular area of $2.0 \mathrm{~cm}^{2}$ around the implant was removed, immersed in $10 \%(\mathrm{w} / \mathrm{v})$ formalin for 12 hours, transferred to $70 \%(\mathrm{v} / \mathrm{v})$ ethanol solution for 24 hours, and dehydrated with ascending grades of alcohol. The samples were embedded in paraffin, sliced into $5 \mu \mathrm{m}$-thickness and mounted in slides. Lastly, they were stained with hematoxylin and eosin (Sigma-Aldrich, Germany).

\section{RESULTS AND DISCUSSION}

\subsection{Characterization of PHB and PHB/PPG films}

Polymeric blends with PHB are most often prepared in solution from the molten state of the blend components. The interaction between the blend components is important to improve PHB properties. The addition of polymers or stabilizers is very effective to improve the thermal stability and processability of PHB [45]. In view of this, FTIR spectroscopy is widely used in the characterization of polymeric matrices because of its ability to provide information about the amorphous and crystalline regions. Figure 1A shows FTIR spectra of PHB and PHB/PPG films and Simv..

The PHB showed bands at $1720 \mathrm{~cm}^{-1}$ ( $\mathrm{C}=\mathrm{O}$ stretching), $1274 \mathrm{~cm}^{-1}$ (C-O-C symmetrical stretching), and $978 \mathrm{~cm}^{-1}$ (C-C stretching), which refer to crystalline regions, and bands at $1459 \mathrm{~cm}^{-1}\left(\mathrm{CH}_{3}\right.$ asymmetric deforming) and $1228 \mathrm{~cm}^{-1}$ (C-O-C stretching), from amorphous regions. Our findings were similar to those found in the literature [46, 47]. The addition of $10 \%$ PPG to PHB modified the band at $1732 \mathrm{~cm}^{-1}$, suggesting that methyl groups of PPG are interacting with PHB carbonyl groups, inducing the formation of a crystalline/amorphous transition phase [48]. The FTIR spectra of Simv. showed characteristic peaks at 3548 $\mathrm{cm}^{-1}$ (O-H stretching vibration), $2955 \mathrm{~cm}^{-1}$ and $2877 \mathrm{~cm}^{-1}$ (C-H stretching vibration), and $1699 \mathrm{~cm}^{-1}$ (stretching vibration of $\mathrm{C}-\mathrm{O}$ and $\mathrm{C}=\mathrm{O}$ carbonyl groups) [49].

The presence of Simv. to the films modified the carbonyl band at $1720 \mathrm{~cm}^{-1}$. It is notable that intensity of this peak was slightly reduced after adding 5\% of Simv. to PHB films. With the increase of Simv. concentration (to 25\%) an even more significant reduction was observed (Figure 1B). For PHB/PPG films a similar behavior was observed, however, the reduction was noted only in the high concentration of Simv. (Figure 1C).

In the study performed by TOLOUE and collaborators [17], the carbonyl band becomes sharper after adding Alumina to PHB. According to the authors, the Alumina act as nucleating agents, leading to an increase in this peak, which is related to the crystalline phase of the scaffolds. Crystallinity is an interesting target, that could modify the bioavailability of drugs and mechanical properties of systems [17, 50]. In view of this, in our study, films containing $5 \%$ of Simv. could be employed as a slow-release device because they can release the drug over an increased amount of time, while films with $25 \%$ of Simv. are more unstable and 
can release the Simv. faster [51]. However, further investigation should be carried out to quantify the crystallinity and its influence on drug delivery.

A

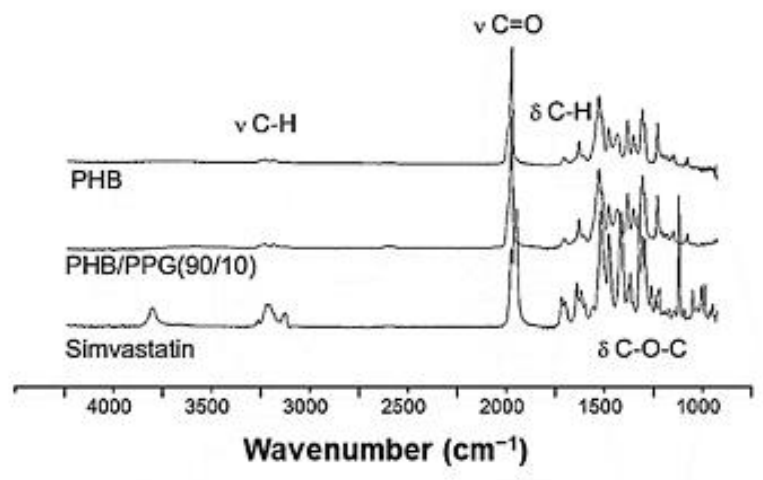

B

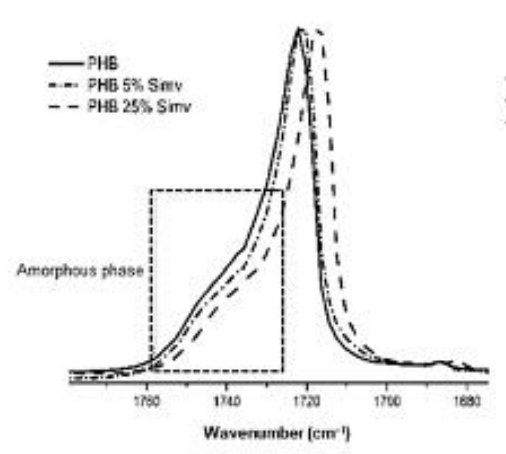

C

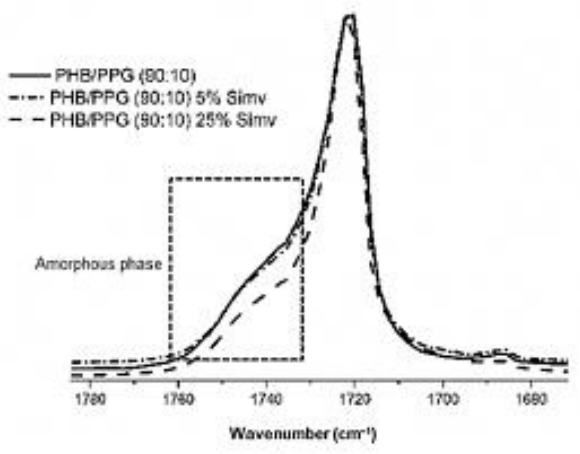

Figure 1: A) FTIR A a of the PHB, PHB/PPG blend, and Simv. B) FTIR spectra for carbonyl region of PHB, PHB with 5\% Simv. and PHB with 25\% Simv. C) FTIR spectra for carbonyl region of PHB/PPG, PHB/PPG with 5\% Simv., and PHB/PPG with $25 \%$ Simv.

Regarding thermic properties, PHB films showed an onset temperature of $260^{\circ} \mathrm{C}$ and degradation temperature of $269{ }^{\circ} \mathrm{C}$, while for PHB/PPG films these values were $278^{\circ} \mathrm{C}$ and $286{ }^{\circ} \mathrm{C}$, respectively (Table 2). As expected, $\mathrm{PPG}$ is responsible for an increase in the stability of the polymeric matrix (Figure 2A). PHB/PPG 90:10 blends were described for the first time by Roa and colleagues [34]. According to the authors, the presence of PPG at $10 \%$ in the PHB phase difficult crystal formation and consequently increases decomposition temperature, which can contribute terms of the processability of PHB. Also, they speculate that it is related to the highest miscibility for this blend.

The addition of Simv. in films of PHB promoted an increase in their degradation temperature (Figure 2B). A study using Simv. in an alginate composite film showed that Simv. also improves the stability of the systems because of an increase in the degradation temperature [52]. The onset temperature of Simv. is $281^{\circ} \mathrm{C}$ and the degradation temperature is $348^{\circ} \mathrm{C}$, which implies superior drug stability compared to the polymeric films. Thus, the higher the percentage of Simv., the more the thermal characteristics approach the drug.

PHB/PPG films with the presence of $25 \%$ of Simv. showed a decrease in the degradation temperature. However, this effect was not observed in films with only 5\% of Simv. (Figure 2C). Higher percentages of Simv., lead to a formation of more heterogeneous structures, which contributes to facilitate their degradation and reduces their thermal stability. The obtained data correspond to the results obtained in the study of PARHI and SURESH [53], in which membranes, composed of polyvinyl alcohol blend and Eudragit, containing plasticizer and using Simv. as a drug, were developed. The authors observed that the presence of Simv. in the concentration of $2 \%$ contributes positively to an increase in the film degradation temperature. However, when in greater quantity, the drug destabilizes the system and facilitates its degradation which corroborates with the results obtained from this study. 
Table 2: Results of thermal analysis of PHB and PHB/PPG films in presence of Simv.

\begin{tabular}{l|c|c|c|c}
\hline & $\mathbf{T}_{\mathrm{m}}\left({ }^{\circ} \mathbf{C}\right)$ & $\mathbf{T}_{\text {onset }}\left({ }^{\circ} \mathbf{C}\right)$ & $\mathbf{T}_{\mathbf{d}}\left({ }^{\circ} \mathbf{C}\right)$ & Residue \\
\hline PHB & 142 & 260 & 269 & $<1 \%$ \\
\hline PHB 5\% Simv. & 136 & 280 & 286 & $<1 \%$ \\
\hline PHB 25\% Simv. & 131 & 276 & 286 & $<1 \%$ \\
\hline PHB/PPG (90:10) & 141 & 278 & 286 & $<1 \%$ \\
\hline PHB/PPB (90:10) 5\% Simv. & 124 & 279 & 295 & $<1 \%$ \\
\hline PHB/PPB (90:10) 25\% Simv. & 127 & 269 & 286 & $<1 \%$ \\
\hline Simv. & 138 & 281 & 348 & $<1 \%$ \\
\hline
\end{tabular}

Legends: $T_{m}$ : melting temperature; $T_{\text {onset }}$ : onset temperature; $T_{d}$ : maximum decomposition temperature.
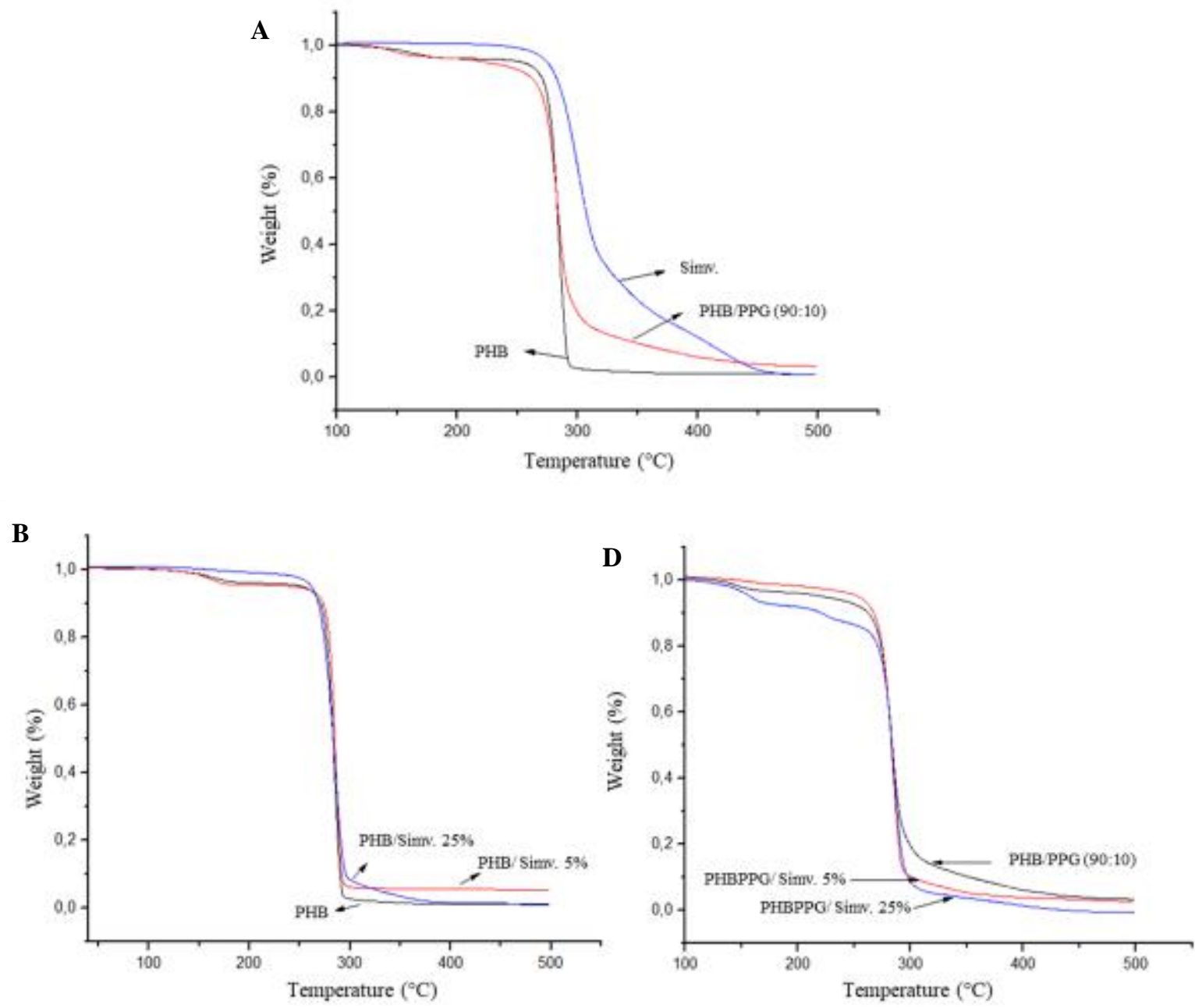

Figure 2: Thermal degradation profile and derivative curves of thermogravimetry for a) PHB, PHB/PPG (90:10) and Simv., b) PHB, PHB with 5\% of Simv. and PHB with 25\% of Simv., and c) PHB/PPG (90:10), PHB/PPG (90:10) with $5 \%$ of Simv. and PHB/PPG (90:10) with $25 \%$ of Simv. 


\subsection{Morphological Analysis}

SEM analysis was used to evaluate the morphological structure of PHB and PHB/PPG films in the presence or absence of Simv.. The surfaces of the films had a rough texture with large porous (Figure $3 \mathrm{~A}$ ), which became more regular with the addition of PPG (Figure $3 \mathrm{D}$ ). The addition of Simv. was responsible for a smoother surface, in PHB film with 5\% of Simv (Figure 3B) and PHB film with 25\% of Simv (Figure 3 C) and PHB/PPG with 5\% of Simv (Figure 3 E). But, in films of PHB/PPG containing 25\% of Simv. (Figure $3 \mathrm{~F}$ ), was observed on a rugous surface.
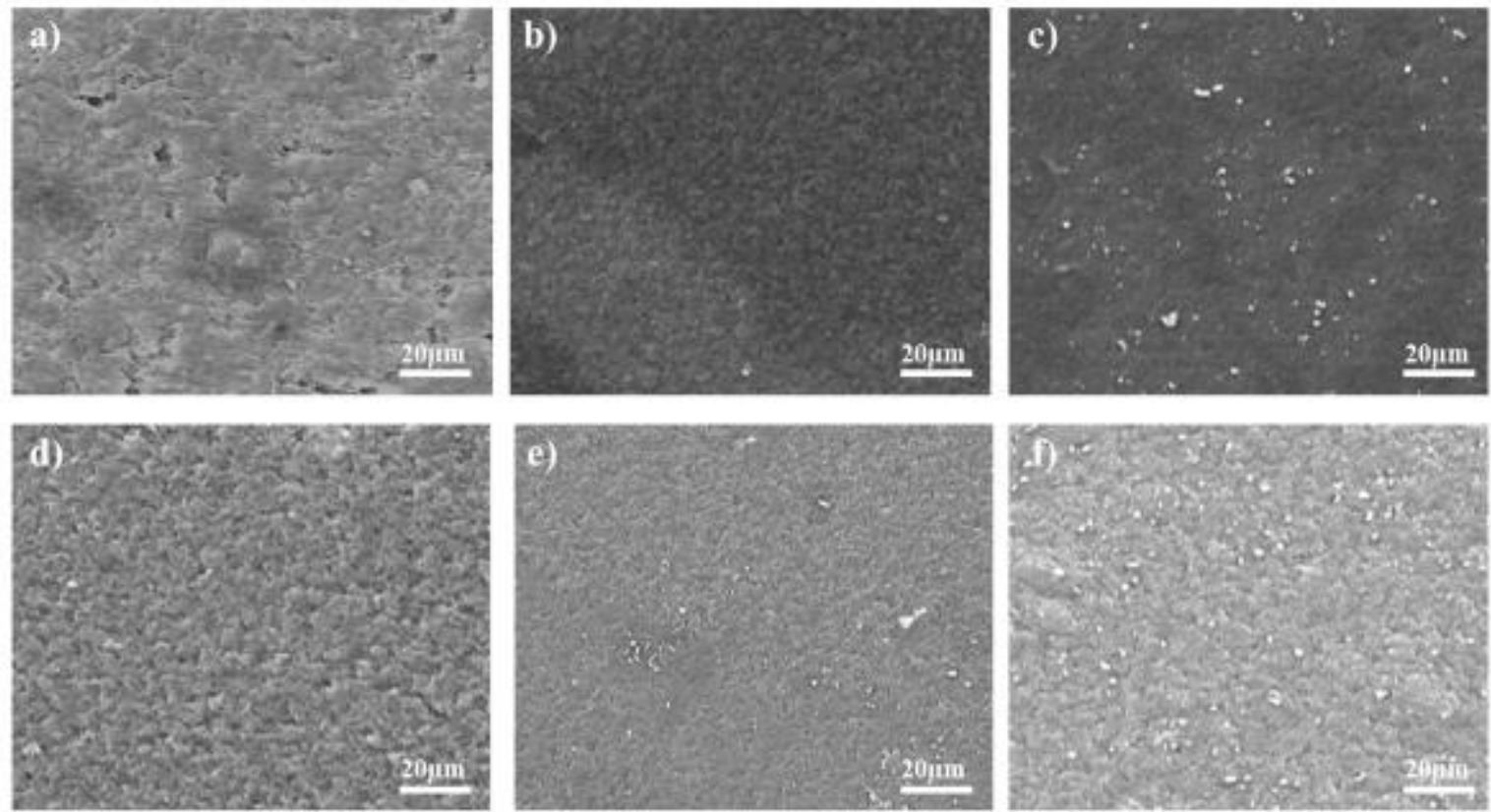

Figure 3. SEM micrographs of the surfaces of (A) PHB, (B) PHB 5\% Simv., (C) PHB 25\% Simv., (D) PHB/PPG (90:10), (E) PHB/PPG (90:10) 5\% Simv., and (F) PHB/PPG (90:10) 25\% Simv. films. Scale bar: $20 \mu \mathrm{m}$.

Some studies have correlated the presence of clearer points in the matrix with drug crystals [53, 54]. Furthermore, the formation of small clusters of crystals when a substantial amount of drug is present in the system can be inferred. Similar findings were observed by REZVANIAN and collaborators [55] who reported the presence of crystalline particles at the surface due to the distribution of Simv. in the polymeric matrix of the film.

Figure 4 shows the microscopic surface of PHB and PHB/PPG films containing Simv. in bright and polarized (dark) fields. Photomicrographs showed the presence of dark particles indicating that Simv. was heterogeneously dispersed throughout the polymeric matrix. In the polarized light, the presence of crystals (indicated by white arrow) was detected. In films loaded with $25 \%$ of Simv., dark points were observed in the bright fields in larger sizes. We can also observe these structures, as bright solids, under cross-polar fields. The films showed a uniform appearance, with no phase separation or noticeable cracks. Simv. appeared as rod-like crystalline particles under both bright and polarized fields $[52,56]$. 

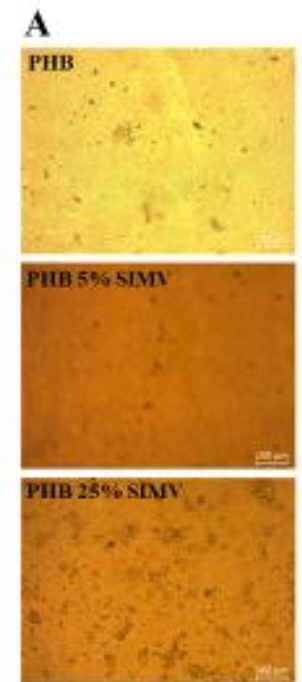
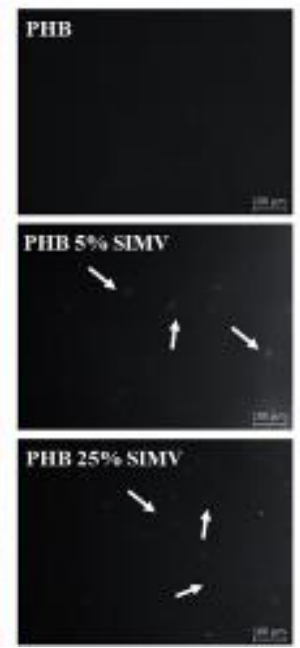

B
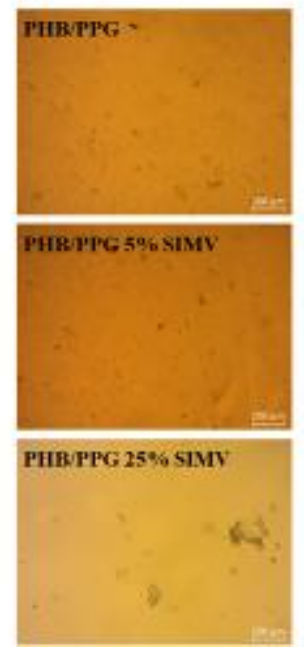
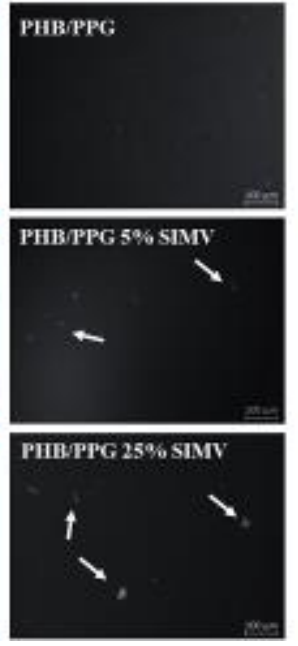

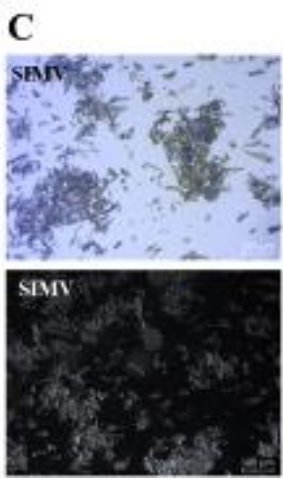

Figure. 4: Microscopic images of (A) PHB films, (B) PHB/PPG films, and Simv. viewed under bright (left column) and polarized (right column) light. The arrows indicate the presence of crystals. (C) Simv. particles under both bright and polarized fields. Scale bar: $100 \mu \mathrm{m}$.

\subsection{In vitro degradation test}

The degradation of PHB and PHB/PPG films containing Simv. was evaluated by in vitro degradation test (Figure 5). At the end of the study period, PHB/PPG films showed a slightly higher weight loss $(13,57 \pm 0,59 \%)$ than the PHB films $(9,43 \pm 0,60 \%)$. The presence of Simv. contributes to weight loss. PHB 5\%

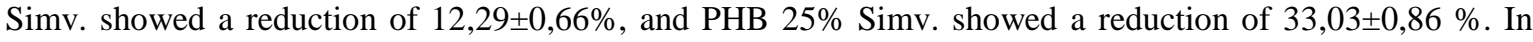
PHB/PPG films containing Simv., the weight loss was more intense $(19,40 \pm 0,65$ and 53,17 $\pm 0,84$ for films containing $5 \%$ and $25 \%$ of Simv., respectively).
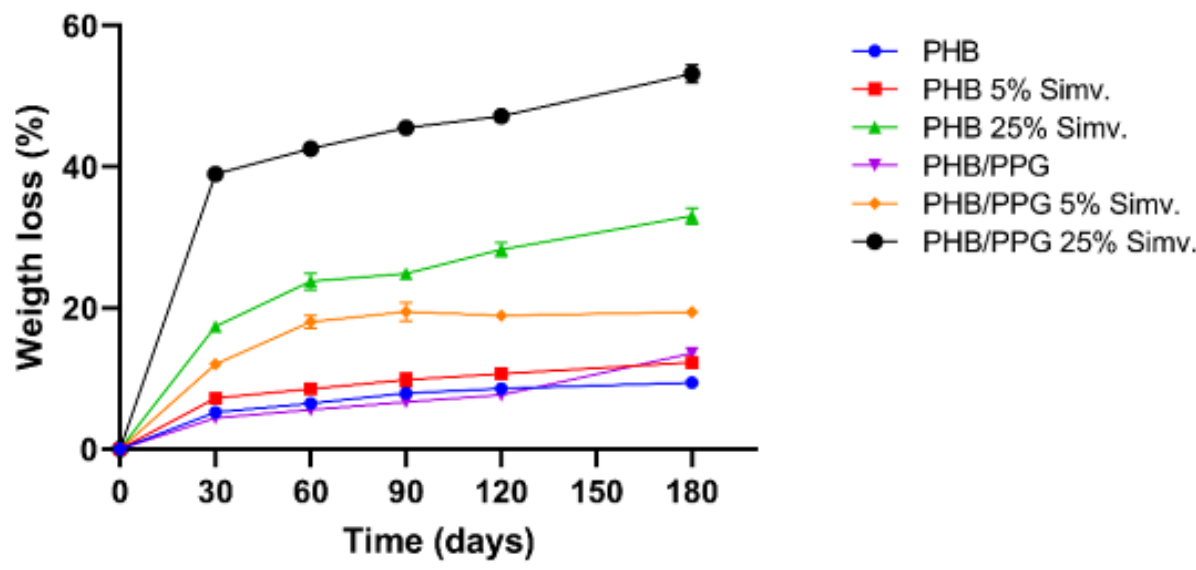

Figure 5. Degradation profiles of PHB and PHB/PPG films. Results are expressed as mean \pm SD from six independent experiments.

The film containing $25 \%$ of Simv. was the one that showed expressive loss of mass. This loss was approximately four times greater than the loss of the film without drug. This effect can be explained because of the instability caused in the polymeric matrix by a great amount of drug, as observed before. Similar findings were found in the study by YASSUE-CORDEIRO et al. 2015 [57], in which the mass loss of chitosan-based films and the amount of silver in each system were related. They observed that the device that contained a higher percentage of silver also had a more expressive mass loss. Therefore, in the next steps of this work, we intend to go further with the Simvastatine release study, using methods of literature to quantify this drug in the medium for each time tested. 


\subsection{Biocompatibility in vivo}

The in vivo biodegradation of PHB / PPG films containing Simv. has been investigated because of the potential usage of these devices in vivo. Biocompatibility of PHB and PHB/PPG was evaluated by histological analysis 60 days after insertion of the films in the mouse. The films were under the epithelial tissue (triangle). No morphological tissue alterations or areas of necrosis were seen around the inserted films. Besides that, a thin fibrous capsule (black arrows) was observed in all tested groups (Figure 6). However, as the film was not fully absorbed by the body, chronic inflammation was observed. The inflammation is characterized by the presence of an infiltrate of mononuclear cells, among them, lymphocytes, plasma cells, and macrophages.

Macrophages secrete proteins that induce the formation of a fibrous capsule around the implant. Therefore, the degree of inflammation that the device will entail will directly influence the fibrous capsule around the material [58]. Macrophages are also responsible for secreting proteins that induce fibrous capsule formation by means of pro-angiogenic cytokines and mediators of biomaterial degradation, which will aid in the process of implant incorporation into the adjacent tissue [59, 60]. Several studies on the insertion of biodegradable polymer implants have shown similar results, which reaffirms the potential of these polymers to be used as a drug delivery system [61-63].

The presence of Simv. in the system did not alter the results obtained by the histological analysis. However, in the groups with 25\% of Simv. (Figures 6C and 6F), a more pronounced degradation was observed, mainly in the PHB/PPG film (asterisks). In a study conducted by ASSAF, DUEK, and OLIVEIRA [64] the induction of bone tissue growth by PLGA membranes containing Simv. implanted in the fracture area was investigated. This study obtained positive results and observed a greater amount of bone tissue in the organisms that contained the drug, which promoted healing. Also, the membrane did not develop an acute inflammatory response within 60 days, as well as the films analyzed in this research.
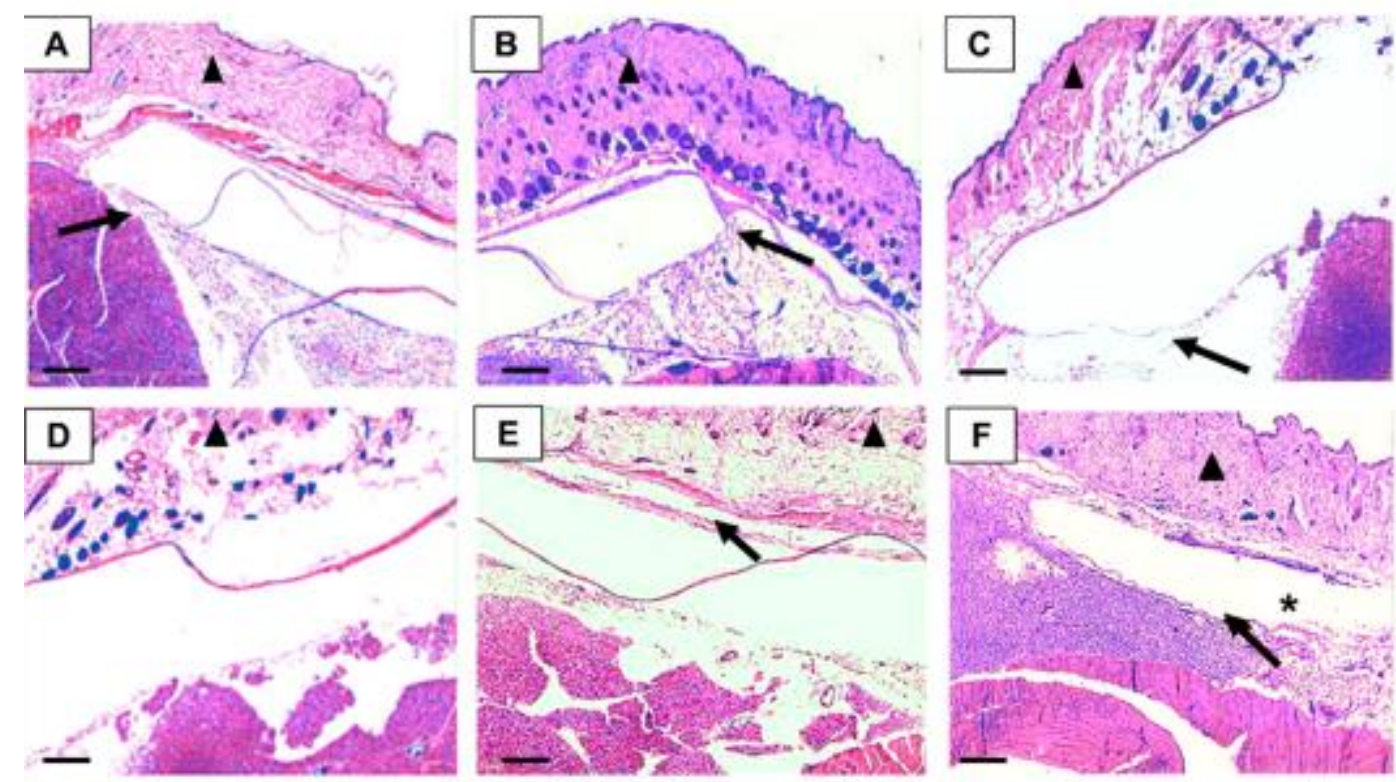

Figure 6. Histological analysis of the implant region after 60 days. A) PHB B) PHB with 5\% Simv. C) PHB with 25\% Simv. D) PHB/PPG. E) PHB/PPG 5\% Simv. F) PHB/PPG 25\% Simv. Scale bar: $10 \mathrm{~mm}$. Black arrows show the fibrous capsule around the implanted films and the triangle indicates the epithelial tissue. Asterisk highlight the intense degradation suffered by films of PHB/PPG with $25 \%$ of Simv.

Finally, the present study has some limitations. It did not involve any investigation regarding how the mechanical properties influence the film's biocompatibility. Biomedical devices' architecture influences cell viability, proliferation, and differentiation. Thus, they should be compatible with the implant site to allows diffusion of nutrients and cell adhesion [65, 66]. Therefore, for a better understanding of the biocompatibility of PHB/PPG films, more tests need to be conducted. 


\section{CONCLUSION}

Control drug delivery systems promote the sustained release of the drug for an extended period, which increases the effectiveness of treatment and reduces the adverse effects. Thus, it increases the interest in developing new biomedical devices that can also act as therapeutic agent delivery platforms. Owing to their excellent biocompatibility and physicochemical properties, numerous polymers have been tested.

In this study, we report the use of PHB films in the presence of a second polymer, PPG, and Simv. for biomedical applications. The films were obtained by dissolving PHB or blend (PHB/PPG 90:10) and Simv. (5\% or $25 \%$ ) by casting.

Our results showed that PHB was able to form a cohesive film and the presence of PPG promoted increased stability of the polymeric matrix. Additionally, the presence of 5\% Simv. does not affect the film homogeneity, but the increase of Simv. concentration (i.e., to 25\%), leads to instability of the PHB/PPG films.

In vitro degradation study proved that films of PHB/PPG underwent superior degradation in contrast to the PHB films. Moreover, this weight loss was higher in films that containing $25 \%$ of Simv., which can attributes to a faster releasing the drug in this group.

In vivo study revealed that none of the films interacting with the animal's organism were rejected, which makes it possible to use them as implants. Overall, it was possible to infer that PHB/PPG films represent a potential polymeric matrix for internal devices for control drug release. Thus, additional experiments are required to verify the efficacy of drug release from these films.

\section{ACKNOWLEDGMENTS}

The authors would like to thank Fundação de Amparo à Pesquisa do Estado de Minas Gerais-Fapemig, Conselho Nacional de Desenvolvimento Científico e Tecnológico - CNPq - Project: 422769/2016-9 and CAPES (Coordenação de Aperfeiçoamento de Pessoal de Nível Superior) for the financial support.

\section{BIBLIOGRAPHY}

[1] WONG, K.K.L., TU, J., SUN, Z., et al., Methods in research and development of biomedical devices, 2013.

[2] MARJANOVIĆ-BALABAN, Ž., JELIĆ, D., "Polymeric Biomaterials in Clinical Practice," Biomaterials in Clinical Practice, Cham, Springer International Publishing, pp. 101-117, 2018.

[3] WANG, M., TANG, T., MENDHI, J., et al., "Dose controlled nitric oxide-based strategies for antibacterial property in biomedical devices," Applied Materials Today, v. 17, Elsevier (Singapore) Pte Ltd, pp. 42-54, 01-Apr-2020.

[4] WANG, M., TANG, T., "Surface treatment strategies to combat implant-related infection from the beginning," Journal of Orthopaedic Translation, v. 17, Elsevier (Singapore) Pte Ltd, pp. 42-54, 01-Apr2019.

[5] MONDAL, S., PAL, U., "3D hydroxyapatite scaffold for bone regeneration and local drug delivery applications," Journal of Drug Delivery Science and Technology, v. 53, Editions de Sante, p. 101131, 01Oct-2019.

[6] SONG, R., MURPHY, M., LI, C., et al., "Current development of biodegradable polymeric materials for biomedical applications," Drug Design, Development and Therapy, 2018.

[7] MISRA, A., SHAHIWALA, A., Applications of Polymers in Drug Delivery, ed. 2a , Shropshire, Reino Unido, Smithers Rapra Technology Ltd, 2021.

[8] SUR, S., RATHORE, A., DAVE, V., et al., "Recent developments in functionalized polymer nanoparticles for efficient drug delivery system," Nano-Structures and Nano-Objects, v. 20, Elsevier B.V., p. 100397, 01-Oct-2019.

[9] LENGYEL, M., KÁLlAI-SZABÓ, N., ANTAL, V., et al., Microparticles, Microspheres, and Microcapsules for Advanced Drug Delivery, Scientia Pharmaceutica, v. 87, n. 3, p. 20, Aug. 2019.

[10] SAVICKI, C., CAMARGO, N.H.A., GEMELLI, E., et al., Carregamento e caracterização do fármaco carboplatina na microestrutura microporosa do biomaterial granulado bifásico micro e nanoestruturado de fosfato de cálcio, Revista Materia, v. 24, n. 1, 2019. 
[11] STEWART, S.A., DOMÍNGUEZ-ROBLES, J., DONNELLY, R.F., et al., "Implantable polymeric drug delivery devices: Classification, manufacture, materials, and clinical applications," Polymers, v. 10, n. 12, MDPI AG, p. 1379, 12-Dec-2018.

[12] KLEBER, M., REARDON, P., "Biopolymers and Macromolecules," pp. 1-5, 2017.

[13] ABBASIAN, M., MASSOUMI, B., MOHAMMAD-REZAEI, R., et al., "Scaffolding polymeric biomaterials: Are naturally occurring biological macromolecules more appropriate for tissue engineering?," International Journal of Biological Macromolecules, 2019.

[14] JIA, K., CAO, R., HUA, D.H., et al., Study of Class I and Class III Polyhydroxyalkanoate (PHA) Synthases with Substrates Containing a Modified Side Chain, Biomacromolecules, v. 17, n. 4, pp. 1477$1485,2016$.

[15] TAN, G.Y.A., CHEN, C.L., LI, L., et al., Start a research on biopolymer polyhydroxyalkanoate (PHA): A review, Polymers, v. 6, n. 3, pp. 706-754, 2014.

[16] GINJUPALLI, K., SHAVI, G.V., AVERINENI, R.K., et al., "Poly( $\alpha$-hydroxy acid) based polymers: A review on material and degradation aspects," Polymer Degradation and Stability, 2017.

[17] TOLOUE, E.B., KARBASI, S., SALEHI, H., et al., Potential of an electrospun composite scaffold of poly (3-hydroxybutyrate)-chitosan/alumina nanowires in bone tissue engineering applications, Materials Science and Engineering C, v. 99, pp. 1075-1091, Jun. 2019.

[18] BABOS, G., RYDZ, J., KAWALEC, M., et al., Poly(3-Hydroxybutyrate)-Based Nanoparticles for Sorafenib and Doxorubicin Anticancer Drug Delivery, International Journal of Molecular Sciences, v. 21, n. 19, p. 7312, Oct. 2020.

[19] PEZZIN, S.H., OLALlA, Á.S., TORRES, E.G., et al., Preparação de membranas de PHB por eletrofiação e caracterização para aplicações em engenharia tecidual, Revista Materia, v. 23, n. 4, 2018.

[20] ZHONG, Y., GODWIN, P., JIN, Y., et al., Biodegradable polymers and green-based antimicrobial packaging materials: A mini-review, Advanced Industrial and Engineering Polymer Research, v. 3, n. 1, pp. 27-35, Jan. 2020.

[21] KABIR, E., KAUR, R., LEE, J., et al., "Prospects of biopolymer technology as an alternative option for non-degradable plastics and sustainable management of plastic wastes," Journal of Cleaner Production, v. 258, Elsevier Ltd, p. 120536, 10-Jun-2020.

[22] OL'KHOV, A.A., AKATOV, V.S., PROSVIRIN, A.A., et al., Implants for Reconstructive Surgery Based on Electrospun Poly(3-hydroxybutyrate) Fibers, Fibre Chemistry, v. 49, n. 3, pp. 222-226, Sep. 2017.

[23] DE SOUSA, W.J.B., BARBOSA, R.C., FOOK, M.V.L., et al., Membranas de polihidroxibutirato com hidroxiapatita para utilização como biomaterial, Revista Materia, 2017.

[24] ZHUIKOV, V.A., AKOULINA, E.A., CHESNOKOVA, D. V., et al., The Growth of 3T3 Fibroblasts on PHB, PLA and PHB/PLA Blend Films at Different Stages of Their Biodegradation In Vitro, Polymers, v. 13, n. 1, p. 108, Dec. 2020.

[25] BAROUTI, G., JAFFREDO, C.G., GUILLAUME, S.M., Advances in drug delivery systems based on synthetic poly(hydroxybutyrate) (co)polymers, Progress in Polymer Science, v. 73, pp. 1-31, 2017.

[26] RAZA, Z.A., KHALIL, S., ABID, S., "Recent progress in development and chemical modification of poly(hydroxybutyrate)-based blends for potential medical applications," International Journal of Biological Macromolecules, v. 160, Elsevier B.V., pp. 77-100, 01-Oct-2020.

[27] HEYDARI, P., VARShOSAZ, J., ZARGAR KHARAZI, A., et al., Preparation and evaluation of poly glycerol sebacate/poly hydroxy butyrate core-shell electrospun nanofibers with sequentially release of ciprofloxacin and simvastatin in wound dressings, Polymers for Advanced Technologies, v. 29, n. 6, pp. 1795-1803, Jun. 2018.

[28] ARRIETA, M.P., LÓPEZ, J., HERNÁNDEZ, A., et al., Ternary PLA-PHB-Limonene blends intended for biodegradable food packaging applications, European Polymer Journal, v. 50, n. 1, pp. 255-270, 2014.

[29] GARCIA-GARCIA, D., FERRI, J.M., BORONAT, T., et al., Processing and characterization of binary poly(hydroxybutyrate) (PHB) and poly(caprolactone) (PCL) blends with improved impact properties, Polymer Bulletin, v. 73, n. 12, pp. 3333-3350, 2016.

[30] ZHUIKOV, V.A., BONARTSEV, A.P., ZHARKOVA, I.I., et al., Effect of Poly(ethylene glycol) on the 
Ultrastructure and Physicochemical Properties of the Poly(3-hydroxybutyrate), Macromolecular Symposia, v. 375, n. 1, p. 1600189, Oct. 2017.

[31] CAVAlCANTE, M.P., TOLEDO, A.L.M.M., RODRIGUES, E.J.R., et al., Correlation between traditional techniques and TD-NMR to determine the morphology of PHB/PCL blends, Polymer Testing, v. 58, pp. 159-165, Apr. 2017.

[32] GIRetova, M., MedVecky, L., Petrovova, E., et al., Polyhydroxybutyrate/Chitosan 3D Scaffolds Promote In Vitro and In Vivo Chondrogenesis, Applied Biochemistry and Biotechnology, v. 189, n. 2, pp. 556-575, Oct. 2019.

[33] FRONE, A.N., BATALU, D., CHIULAN, I., et al., Morpho-structural, thermal and mechanical properties of PLA/PHB/Cellulose biodegradable nanocomposites obtained by compression molding, extrusion, and $3 d$ printing, Nanomaterials, v. 10, n. 1, p. 51, Jan. 2020.

[34] ROA, J.P.B., PATRÍCIA, P.S., ORÉFICE, R.L., et al., Improvement of the thermal properties of poly(3hydroxybutyrate) (PHB) by low molecular weight polypropylene glycol (LMWPPG) addition, Journal of Applied Polymer Science, v. 128, n. 5, pp. 3019-3025, 2013.

[35] RAJAN, M., PRAPHAKAR, R.A., GOVINDARAJ, D., et al., Cytotoxicity assessment of palbociclibloaded chitosan-polypropylene glycol nano vehicles for cancer chemotherapy, Materials Today Chemistry, v. 6, pp. 26-33, Dec. 2017.

[36] SIDDIQUI, F.M., LANGEFELD, C.D., MOOMAW, C.J., et al., Use of Statins and Outcomes in Intracerebral Hemorrhage Patients, Stroke, v. 48, n. 8, pp. 2098-2104, 2017.

[37] ANANTHAKRISHNAN, A.N., CAGAN, A., CAI, T., et al., Statin Use Is Associated With Reduced Risk of Colorectal Cancer in Patients With Inflammatory Bowel Diseases, Clinical Gastroenterology and Hepatology, v. 14, n. 7, pp. 973-979, 2016.

[38] GENTILE, P., NANDAGIRI, V.K., DALY, J., et al., Localised controlled release of simvastatin from porous chitosan-gelatin scaffolds engrafted with simvastatin loaded PLGA-microparticles for bone tissue engineering application, Materials Science and Engineering C, v. 59, pp. 249-257, 2016.

[39] ALAM, M., AHMED, S., NIKITA, et al., Chemical engineering of a lipid nano-scaffold for the solubility enhancement of an antihyperlipidaemic drug, simvastatin; preparation, optimization, physicochemical characterization and pharmacodynamic study, Artificial Cells, Nanomedicine and Biotechnology, v. 0, n. 0, pp. 1-12, 2017.

[40] ZHANG, P., HAN, F., LI, Y., et al., Local delivery of controlled-release simvastatin to improve the biocompatibility of polyethylene terephthalate artificial ligaments for reconstruction of the anterior cruciate ligament, International Journal of Nanomedicine, v. 11, pp. 465-478, 2016.

[41] FANG, W., ZHAO, S., HE, F., et al., Influence of simvastatin-loaded implants on osseointegration in an ovariectomized animal model, BioMed Research International, v. 2015, 2015.

[42] YU, W.L., SUN, T.W., QI, C., et al., Enhanced osteogenesis and angiogenesis by mesoporous hydroxyapatite microspheres-derived simvastatin sustained release system for superior bone regeneration, Scientific Reports, v. 7, n. 1, pp. 1-16, Mar. 2017.

[43] SADAT-SHOJAI, M., KHORASANI, M.-T., DINPANAH-KHOSHDARGI, E., et al., Synthesis methods for nanosized hydroxyapatite with diverse structures, Acta Biomaterialia, v. 9, n. 8, pp. 7591-7621, Aug. 2013.

[44] VANIN, M., SANTANA, C.C., TORRIANI, Í.L., et al., Estudo da degradação in vitro de blendas de poli(beta-hidroxibutirato) (PHB) / poli(L-ácido latico) (PLLA) na forma de filmes, Polímeros, v. 14, n. 3, pp. 187-193, Sep. 2004.

[45] AURIEMMA, M., PISCITELLI, A., PASQUINO, R., et al., Blending poly(3-hydroxybutyrate) with tannic acid: Influence of a polyphenolic natural additive on the rheological and thermal behavior, European Polymer Journal, v. 63, pp. 123-131, 2015.

[46] MOUSAVIOUN, P., HALLEY, P.J., DOHERTY, W.O.S., Thermophysical properties and rheology of PHB/lignin blends, Industrial Crops and Products, v. 50, pp. 270-275, 2013.

[47] DEBUISSY, T., POLLET, E., AVÉROUS, L., Synthesis and characterization of block poly(ester-etherurethane)s from bacterial poly(3-hydroxybutyrate) oligomers, Journal of Polymer Science, Part A: Polymer Chemistry, v. 55, n. 11, pp. 1949-1961, Jun. 2017. 
[48] ROA, J.P.B., MANO, V., FAUSTINO, P.B., et al., Síntese e caracterização do copolímero poli(3-

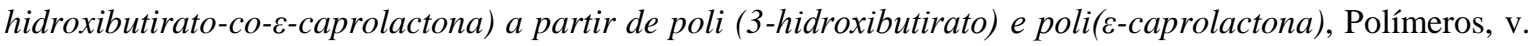
20, n. 3, pp. 221-226, Oct. 2010.

[49] PAVIA, D.L., LAMPMAN, G.M., KRIZ, G.S., "Introduction to Spectroscopy third edition," Thomson Learning, Inc., p. 579, 2001.

[50] MENDONÇA, R.H., DE OLIVEIRA MEIGA, T., DA COSTA, M.F., et al., Production of 3D scaffolds applied to tissue engineering using chitosan swelling as a porogenic agent, Journal of Applied Polymer Science, v. 129, n. 2, pp. 614-625, Jul. 2013.

[51] RIZVI, S.Z.H., SHAH, F.A., KHAN, N., et al., Simvastatin-loaded solid lipid nanoparticles for enhanced anti-hyperlipidemic activity in hyperlipidemia animal model, International Journal of Pharmaceutics, v. 560, pp. 136-143, Apr. 2019.

[52] REZVANIAN, M., MOHD AMIN, M.C.I., NG, S.F., Development and physicochemical characterization of alginate composite film loaded with simvastatin as a potential wound dressing, Carbohydrate Polymers, v. 137, pp. 295-304, 2016.

[53] PARHI, R., SURESH, P., Formulation optimization and characterization of transdermal film of simvastatin by response surface methodology, Materials Science and Engineering C, v. 58, pp. 331-341, 2016.

[54] LIU, Y., ZHENG, Z., ZARA, J.N., et al., The antimicrobial and osteoinductive properties of silver nanoparticle/poly (dl-lactic-co-glycolic acid)-coated stainless steel, Biomaterials, v. 33, n. 34, pp. 87458756, 2012.

[55] REZVANIAN, M., AHMAD, N., AMIN, M.C.I.M. , et al., Optimization, characterization, and in vitro assessment of alginate-pectin ionic cross-linked hydrogel film for wound dressing applications, International Journal of Biological Macromolecules, v. 97, pp. 131-140, 2017,

[56] ROMO-URIBE, A., MENESES-ACOSTA, A., DOMÍNGUEZ-DÍAZ, M., Viability of HEK 293 cells on poly- $\beta$-hydroxybutyrate (PHB) biosynthesized from a mutant Azotobacter vinelandii strain. Cast film and electrospun scaffolds, Materials Science and Engineering C, v. 81, pp. 236-246, 2017.

[57] YASSUE-CORDEIRO, P.H., ZANDONAI, C.H., FERNANDES-MACHADO, N.R.C., Desenvolvimento e caracterização de filmes compósitos de quitosana e zeólitas com prata, Polímeros, v. 25, n. 5, pp. 492-502, 2015.

[58] ABBAS, A.K., LICHTMAN, A.H., PILlAI, S., Imunologia Celular e Molecular - Abbas 8ed-2, Elsevier Editora Ltda, n. 8, pp. 631-667, 2015.

[59] BARR, S., HILL, E.W., BAYAT, A., Functional biocompatibility testing of silicone breast implants and a novel classification system based on surface roughness, Journal of the Mechanical Behavior of Biomedical Materials, v. 75, pp. 75-81, Nov. 2017.

[60] EICKHOFF, R.M., BOLLE, T., KOSSEL, K., et al., Improved biocompatibility of profiled sutures through lower macrophages adhesion, Journal of Biomedical Materials Research - Part B Applied Biomaterials, v. 107, n. 6, pp. 1772-1778, Aug. 2019.

[61] MEISCHEL, M., EICHLER, J., MARTINELLI, E., et al., Adhesive strength of bone-implant interfaces and in-vivo degradation of PHB composites for load-bearing applications, Journal of the Mechanical Behavior of Biomedical Materials, v. 53, pp. 104-118, 2016.

[62] KRUCINSKA, I., ZYWICKA, B., KOMISARCZYK, A., et al., Biological properties of low-toxicity PLGA and PLGA/PHB fibrous nanocomposite implants for osseous tissue regeneration. Part I: Evaluation of potential biotoxicity, Molecules, v. 22, n. 12, p. 2092, Dec. 2017.

[63] KAI, D., ZHANG, K., LIOW, S.S., et al., New Dual Functional PHB-Grafted Lignin Copolymer: Synthesis, Mechanical Properties, and Biocompatibility Studies, 2018.

[64] ASSAF, K., DUEK, E.A. de R., OLIVEIRA, N.M., Efficacy of a combination of simvastatin and poly(DL-lactic-co-glycolic acid) in stimulating the regeneration of Bone Defects, Materials Research, v. 16, n. 1, pp. 215-220, 2013.

[65] PISANI, S., GENTA, I., DORATI, R., et al., Biocompatible polymeric electrospun matrices: Micronanotopography effect on cell behavior, Journal of Applied Polymer Science, v. 137, n. 40, p. 49223, Oct. 2020. 
[66] GAO, J., CHEN, S., TANG, D., et al., Mechanical Properties and Degradability of Electrospun PCL/PLGA Blended Scaffolds as Vascular Grafts, Transactions of Tianjin University, v. 25, n. 2, pp. 152160, Apr. 2019.

\section{ORCID}

Lays Fernanda Nunes Dourado Amauri Pierucci

Juan Pedro Bretas Roa

Álvaro Dutra de Carvalho Júnior
https://orcid.org/0000-0001-5287-455X

https://orcid.org/0000-0003-1871-5058

https://orcid.org/0000-0002-0045-3953

https://orcid.org/0000-0003-4544-9373 